\title{
ECOLOGIA DA INFORMAÇÃO
}

DAVENPORT, Thomas H., PRUSAK, Laurence. Ecologia da informação: por que só a tecnologia não basta para o sucesso na era da informação. Tradução Bernadette Siqueira Abrão. São Paulo : Futura, 1998. 316p.

Este trabalho faz-nos lembrar a história recente da biblioteconomia brasileira, quando a discussão girava em torno do futuro da profissão e do papel do bibliotecário diante das inovações tecnológicas e das conseqüentes mudanças que adviriam com a sociedade saindo da fase da industrialização para entrar na era da informação.

Falar em mudanças tecnológicas e o que estas têm provocado na vida diária do cidadão, na estrutura e comportamentos organizacionais, é hoje lugar-comum.

Presenciamos grandes investimentos em sistemas de informação, aquisição de bases de dados desenvolvidas no exterior e disponiblizadas no Brasil, desenvolvimentos de bases de dados locais etc.

Falava-se no novo profissional da informação que surgia com força total: o analista de sistemas. O receio de que este profissional viesse a substituir o bibliotecário era expresso em artigos, palestras e no cotidiano dos profissionais.

Os mainfraimes, computadores de grande porte, e os grandes sistemas de informação ocupavam os espaços, e com eles, os analistas de sistemas. Navegar num sistema residente num computador de grande porte era tarefa possível somente aos analistas, o que lhes conferia a sensação de serem os guardiães da informação.

De espectador o bibliotecário tornou-se um bom (??) interlocutor junto aos analistas para expressar suas necessidades e obter destes, os recursos tecnológicos aplicados, para viabilizar o cumprimento de sua missão que era disponibilizar e facilitar aos usuários o acesso à informação.

Mesmo neste cenário tecnológico, presenciamos grandes avanços na área de Biblioteconomia no País, na década de 70. De um lado, novos cursos eram criados nas universidades brasileiras e, de outro, recursos em infra-estrutura 
de informação eram alocados nas bibliotecas com a aquisição de acervos, de bases de dados, equipamentos, construção ou ampliação de espaços físicos, etc.

Já no início dos anos 80 falava-se sobre a necessidade de o profissional da informação, mais especificamente, o bibliotecário, preparar-se para as mudanças que se aproximavam. O horizonte apontava, como cenário de médio prazo, a era da informação.

O poder, pensávamos, estava diretamente associado à quantidade de informação que o cidadão, o servidor, ou o gerente detinha e sua capacidade de utilizá-la, sem preocupar-se com o momento de sua utilização. E o bibliotecário, o profissional que utilizava a informação como matéria-prima de seu trabalho, como registro do conhecimento e geração de novos, como se posicionaria vendo esta matéria-prima transformar-se em instrumento de trabalho de tantas outras profissões e disponível para a sociedade no atendimento de suas necessidades básicas de sobrevivência?

No ínício da década de 90, Alvin Tofler indicava que, na sociedade da informação, o mundo estaria dividido em duas partes: os mais rápidos e os mais lentos. Aí a informação adquire, com maior precisão, o seu caráter temporal. De nada adiantaria uma quantidade de informação que não circulasse e não provocasse decisões. Aquele que saísse na frente seria o vitorioso na ocupação dos espaços.

O prenúncio era de que estávamos para iniciar a era da informação, e as mudanças já se faziam sentir. A literatura apontava esta realidade e, nos congressos profissionais, este assunto era uma constante.

Se antes só ouvíamos falar sobre isto e a literatura nos apontava nesta direção, hoje, sentimos no nosso dia-a-dia que as mudanças de que dantes falávamos com tanta paixão, agora as vivemos também com paixão, porém, menos assustados, graças a Deus.

São inegáveis os benefícios do avanço tecnológico, das facilidades promovidas pelo processo de comunicação entre as pessoas. Não sei bem se o processo de globalização é tão benéfico quanto, mas, sem sombra de dúvidas, foi provocado e impulsionou o avanço tecnológico.

E nós, bibliotecários, continuamos, os analistas de sistemas também, cada um no seu lugar procurando conviver com esses avanços e adaptálos aos métodos e rotinas de trabalho, e os profissionais das diversas áreas do conhecimento, cada vez mais, trabalhando de maneira integrada.

Se antes convivíamos com os computadores de grande porte, hoje estamos familiarizados com os micro-computadores. Navegar nos sistemas de informação disponíveis é questão de tempo, não assusta nenhum usuário, nem mesmo o bibliotecário, e tornou-se filosofia de trabalho dos próprios analistas que transferem aos usuários a capacidade de manipular, segundo suas necessidades, os sistemas por eles desenvolvidos.

Se antes a informação era privilégio de uns poucos, hoje torna-se mais disponível e de fácil

Inf.Inf., Londrina, v. 4, n. 1, p. 53-58, jan./jun. 1999 
acesso a todos.

O conceito de gestão da informação e de informação como poder extrapolou barreiras e códigos profissionais.

É sobre isso que Davenport discorre em seu livro, e, ao defender sua tese contemporânea de gestão da informação, remonta ao passado e analisa, numa abordagem histórica, o uso da informação.

Ele, um analista de sistemas, associa-se a um bibliotecário para um aprendizado mais maduro e eficaz sobre o uso da informação, conforme depoimento próprio, pois incomodava-o a orientação e vivência de que informação está diretamente relacionada à tecnologia e de que gerenciar informação é gerenciar recursos tecnológicos.

Ampliar o papel dos profissionais que lidam com a informação, gerenciar a informação em vez da tecnologia, associar os conhecimentos da Biblioteconomia e Ciência da Informação aos da tecnologia e comportamento organizacionais, foram os motivos que impulsionaram a produção dessa obra.

Os avanços tecnológicos privilegiaram mais os aspectos do domínio tecnológico deixando de lado o objetivo principal da informação que é informar, transferir conhecimentos, construir a história etc.

Falar em gerenciar informação significava falar em aumentar os investimentos em equipamentos, ampliar o parque tecnológico, enfim, em gerenciar tecnologia. Esta visão, infelizmente, permanece em alguns espaços e comportamentos gerenciais, até hoje.

Todas estas questões são tratadas nessa obra sob uma nova abordagem. $\mathrm{O}$ autor focaliza a importância de os administradores de informação possuírem uma visão mais ampla das próprias instituições e uma capacidade maior de assimilar as alterações repentinas do mundo dos negócios e adaptar-se às sempre mutantes realidades sociais.

A essa nova abordagem o autor chama de ecologia da informação, que enfatiza o ambiente da informação em sua totalidade, levando em conta: os valores e as crenças empresariais sobre informação(cultura); o modo como as pessoas realmente usam a informação e o que fazem com ela (comportamento e processos de trabalho); as armadilhas que podem interferir no intercâmbio de informações (política); e quais sistemas de informação já estão instalados apropriadamente (tecnologia).

Por sua vez, o processo de gestão da informação está associado aos princípios fundamentais de gestão organizacional. O planejamento do ambiente de informação de uma empresa é tratado em sua totalidade, substituindo a prática de privilegiar pequenos nichos organizacionais independentes, ou seja, concentrar esforços em algumas áreas ( tecnologia, controles, orçamento, por exemplo) em detrimento de outras e do negócio principal das instituições.

O uso eficiente de uma pequena quantidade de informação substitui a preocupação com a 
geração de enormes quantidades de informação.

O ponto essencial dessa nova abordagem é que ela procura devolver o homem ao centro do mundo da informação, colocando a tecnologia a serviço dele (homem) e não no seu comando.

A utilização da expressão ecologia, como metáfora, vem da experiência dos estrategistas de negócios e estudiosos das organizações, a exemplo de Henry Mintzberg.

O autor coloca muito bem a questão da gestão da informação, numa perspectiva de sociedade pós-era da informação, com experiências reais de sucessos e derrotas, contextualizada no século que se aproxima e numa perspectiva integrada das profissões.

Confirmando sua preocupação histórica inicia seu trabalho discorrendo sobre o nosso passado informacional, destacando quatro enfoques dados ao processo de administração da informação, a saber:

a) informação não-estruturada, abordagem mais antiga. Neste estágio, os bibliotecários desempenham papel relevante na organização das informações para torná-las úteis aos usuários, numa atitude passiva de guardiães da informação;

b) capital intelectual ou conhecimento - esta abordagem dá ênfase aos valores pessoais e ao conhecimento acumulado pelas pessoas;

c) informação estruturada em papel - com a explosão bibliográfica, a informação está registrada e surge, com os americanos, o conceito de administração de recursos de informação - ARI, que privilegia a redução da papelada burocrática, incluindo as preocupações com o custo da informação e o seu valor econômico;

d) informação estruturada em computadores - a ênfase nesta abordagem consiste em gerenciar dados computadorizados no lugar da informação propriamente dita, dando maior importância à quantidade e estruturação eficaz dos dados e menos à sua qualidade.

Um capítulo está reservado para os fundamentos teóricos do conceito ecologia da informação, onde são analisados os quatro atributos básicos desse conceito:

a) integração dos diversos tipos de informação;

b) reconhecimento de mudanças evolutivas;

c) ênfase na observação e na descrição;

d) ênfase no comportamento pessoal e informacional.

Uma das riquezas desse livro é que, ao mesmo tempo que o autor apresenta sua fundamentação teórica, ele traz ao leitor exemplos práticos de sua abordagem, fruto da aplicação em empresas. No caso, o setor privado e as empresas multinacionais.

A importância do desenvolvimento de uma estratégia global para o uso da informação é condição básica e representa a possibilidade de fazer escolhas, sem definir um plano imutável. Ca- 
berá ao gerente criar estratégias quanto aos tipos de informações que devem ser focalizadas, quanto àas atividades a enfatizar e quanto à maneira como a informação poderá ajudar a empresa a alcançar seus objetivos.

Em verdade, o gerenciamento da informação pode ser utilizado tanto para distribuir o poder como para centralizá-lo. Algumas instituições efetivamente centralizam o controle da informação, outras empregam técnicas similares para promover o acesso às informações e envolver mais pessoas na tomada de decisão. É, de fato, uma questão de escolha.

A essência da política da informação é formada por quem faz a escolha e pelas conseqüências que essa escolha determina. Neste sentido, quando o autor trata dessa questão, não o faz de maneira isolada. Examina os conflitos internos, o ciúme pela divisão de recursos e as batalhas políticas que os ecologistas informacionais devem esperar.

Alerta, ainda, que os gerentes precisam falar honesta e diretamente sobre a natureza da política que pretendem adotar e como pretendem dirigi-la. Descreve os modelos do federalismo, feudalismo, monarquia e anarquia considerando que um destes pode ser ideal para um determinado tipo de organização.

Associando-se aos conceitos de cultura e desenvolvimento organizacionais, ele aponta o papel principal do ecologista da informação, qual seja mudar a maneira como as pessoas usam a informação, identificar seu comportamento, dosar o nível e quantidade de informação que pode ser percebida e internalizada pelos usuários, e como devem construir uma cultura informacional.

Para entender este processo, ele discute como as pessoas realmente utilizam a informação, o que querem dela e por que têm tanta dificuldade em aceitar e viver mudanças.

Outro ponto tratado nesta obra diz respeito às equipes de informação. $\mathrm{O}$ autor analisa as responsabilidades informacionais de vários profissionais da informação, como os analistas de sistemas, os programadores, os gerentes e demais tecnólogos, os editores, e especialmente os bibliotecários, estes, numa análise bastante realista do papel que desempenham, não só pela sua passividade em face das questões informacionais, mas também, pela sua importância neste processo.

Estudos apontaram que as equipes de informação devem possuir os seguintes atributos:

a) compreensão abrangente da área de atuação e conhecimento da estrutura e função da empresa;

b) conhecimento sobre as diferentes fontes de informações da organização;

c) facilidade de acesso a tecnologias de informação;

d) entendimento político associado à habilidade para exercer liderança; 
e) fortes qualificações para relações interpessoais;

f) expressiva orientação para o conjunto de desempenho do negócio, em vez de submissão a objetivos funcionais da organização.

Administrar a informação não é um fato isolado. Constitui-se um processo completo, ou seja, um conjunto estruturado de atividades que incluem o modo como as instituições obtêm, distribuem e usam a informação e o conhecimento, e, para tanto, identificar todos os passos de um processo informacional - as fontes envolvidas, as pessoas que afetam cada passo, os problemas que surgem - pode indicar o caminho para mudanças que realmente fazem a diferença.

O lugar da tecnologia da informação está reservado ao processo de arquitetura da informação, que se constitui em uma série de ferramentas que adaptam os recursos às necessidades da informação. Um projeto bem-implementado estrutura os dados e facilita seu uso. Não devemos nos esquecer, jamais, que por mais desenvolvidas que sejam, as informações normalmente encontram-se muito dispersas nas organizações.

Finalizando seu estudo, o autor focaliza o ambiente organizacional para a administração da informação, incluindo a situação dos negócios, os investimentos em tecnologia e a estrutura organizacional, não se esquecendo, também, de associar todos esses aspectos ao ambiente externo às organizações, os fatores que interferem no desenvolvimento das instituições, suas parcerias suas dependências etc.

Enfim, este trabalho reúne todas as questões que vêm sendo identificadas pelos profissionais da informação ao se prepararem para enfrentar os desafios futuros, que não são mais futuros, e sim, muito presentes no nosso dia-a-dia neste final de século. É uma obra que todo bibliotecário deve conhecer em sua plenitude.

\section{Adelaide Ramos e Côrte}

Bibliotecária, Mestre em Biblioteconomia e Documentação pela Universidade de Brasília

\section{Title}

Ecology of Information

\section{Título}

Ecología de la Información 